\title{
1. Cooperation, dependence, and eviction: how platform-to-business coopetition relationships should be addressed in mobile telephony ecosystems
}

\author{
Frédéric Marty and Julien Pillot
}

\section{INTRODUCTION}

The current debate on the power of dominant firms in the digital industry is mainly based on the concentration of economic power they achieve and its possible irreversibility. Two issues are of particular concern: (1) How did these firms get such a market power and the ability to upkeep and expand their dominant positions? (2) Are the markets in which these firms compete still challengeable, or would the control over users' data constitute impenetrable barriers to entry?

The competition agencies' capacity to prevent these competitive risks through their M\&A control policies, or to effectively sanction strategies aimed at foreclosing existing or even potential competitors from the market, is frequently challenged. In a way, dominant firms in the digital markets are suspected to own financial and technical resources, as well as nowcasting capabilities, likely to prevent them from any potential competitive threat. Then, any company whose products or services would be likely to contest, even in the long run, the dominant firm market shares would enter a kill zone. A counter-intuitive result should then be highlighted: ecosystem insiders would be particularly exposed to this risk.

Such a situation may seem paradoxical. Indeed, whether the platform is open or closed, it is basically a two-sided market. On the one side, it needs a critical mass of users and, on the other side, it seeks for major industrial partners and developers. Both are required in order to fully exploit cross-network externalities. The literature shows how system integrators stand to gain from creating 
a cooperative ecosystem. ${ }^{1}$ Such cooperation involves contractual mechanisms to distribute financial incentives to ecosystem members, the pooling of (technical) resources and implicit non-competition commitments. For instance, Gawer and Henderson ${ }^{2}$ show that Intel avoided developing products that were potentially competitive to those offered by its complementors, ${ }^{3}$ unless the performance of the latter was unsatisfactory or if it appeared necessary to strengthen incentives for innovation through a competitive threat. As Zhu and $\mathrm{Liu}^{4}$ note: 'By committing to not competing with them Intel could encourage these complementors to make [substantial sector specific] investments.'

In this light, how can we appreciate entry decisions on a market segment previously occupied by a complementor? Is it for substituting its own services to replace elder ones seen as not efficient enough, or does it pertain to a two-stage non-cooperative strategy? After an initial cooperative phase aiming at detecting promising (or potentially disruptive) third-parties' developments, the keystone player may replace them with its own products and services (or take control of the complementor) in a second phase.

Our purpose is to analyze these coopetitive strategies. ${ }^{5}$ How to assess the competitive effects generated by such relationships? The case of a mobile operating system (MOS) illustrates how agreements that financially and technically organize such complementarities may have pro- and anticompetitive effects.

Financial incentives or free provision of resources to complementors, two practices at the heart of the European Commission's Android decision, ${ }^{6}$ can be explained by a search for efficiency. As such, these practices could be defended on the basis of two-sided platform's constraints. Competition law

1 Annabelle Gawer and Michael A. Cusumano, Platform Leadership: How Intel, Microsoft, and Cisco Drive Industry Innovation (Harvard Business School Press, 2002).

2 Annabelle Gawer and Rebecca Henderson, 'Platform Owner Entry and Innovation in Complementary Markets: Evidence from Intel', (2007) Journal of Economics and Management Strategy, 16(1), pp. 1-34.

3 Complementors are independent companies developing complementary products that are interoperable with the technical system developed by the keystone company. Marco Iansiti and Roy Lieven, The Keystone Advantage. What the New Dynamics of Business Ecosystems Means for Strategy, Innovation, and Sustainability (Harvard Business School Press, 2004), p. 272.

4 Feng Zhu and Qihong Liu, 'Competing with Complementors: An Empirical Look at Amazon.com', (2018) Strategic Management Journal, 39(10), pp. 2618-2642.

5 Frédéric Marty and Thierry Warin, 'Innovation in Digital Ecosystems: Challenges and Questions for Competition Policy', (2020) Cahier de Recherche du CIRANO, 2020s-10, February.

6 Google Android (case AT.40099) European Commission Decision, C(2018) 4761 final, 18 July 2018. 
does not sanction business-to-business (B2B) cooperation when it results in promoting economic efficiency or innovation. Hence, in the Android decision, the pre-installation of applications and the remuneration paid to complementors could have been found to be procompetitive rather than considered as part of a foreclosure strategy. The same goes for anti-fragmentation agreements. These could have been justified by safety objectives (both for the app developer and the OS owner) as well as interoperability objectives. To that extent, contractual terms made to third-parties (app developers, terminal manufacturers, and mobile network operators) could be analyzed as part of a logic of complementary developments within an ecosystem.

The latter is both a two-sided structure in the sense of its business model - having to link several sides to unlock value (thus possibly justifying pre-installations and financial incentives) - and in the sense of its technical architecture (requiring rules to guarantee compatibility of developments, such as anti-fragmentation agreements). In a nutshell, each of the three practices that led the European Commission to impose a fine of more than 4 billion euros on Google (profit-sharing, pre-installation of applications and anti-fragmentation agreements) could have been defended on the basis of efficiency, with regards to two-sided platforms' economic and technical specificities. At the opposite end, these ecosystems may give rise to exclusionary or exploitative abuses. Most third-party developers are yet in a situation of economic dependence vis-à-vis the platform's owner. Thus, considering these (inter)dependence relationships may be essential to assess the likelihood of a foreclosure attempt (under Article 102 TFEU), as well as the competitive damages that may result from notified concentrations.

Finally, attention should be paid to the effects of remedies imposed to bring a potential infringement to an end, both in the context of merger control and abuse of dominance cases. Remedies could accidentally harm consumers and competition if they result in the loss of some of the gains flowing from firms' coordination. Similarly, remedies may have insufficient effects, especially if they are pronounced too late, when the integrated firm has fewer incentives to share investments (and value) with its complementors.

Our chapter is structured as follows. First, we introduce how cooperative ecosystems are set up in two-sided platforms, and how complementors benefit from the sharing of technical resources and from financial incentives. Second, we show that this technological and competitive symbiosis can result in economic dependence. Third, we focus on the risks complementors have to assume. We illustrate these risks both by the distortion of competition flowing from asymmetries in data access, and by buy-out strategies aiming at neutralizing potential competitors. At last, in the light of the EU Commission decision in Android, we discuss these coopetitive business models under the prism of 
the damage theory established by the Commission and question the effects of competitive remedies.

\subsection{COOPERATIVE ECOSYSTEMS AND TWO-SIDED MODELS: HOW TO ANALYZE P2B RELATIONSHIPS IN THE CASE OF MOBILE OPERATING SYSTEMS?}

Whether a MOS is open like Google Android or closed like Apple iOS, it implies various stakeholders, including app developers, and relies on cooperative strategies, including from the integrating company itself. Such an organization allows actors to share investments and competences to co-construct a value network. The keystone firm pools boundary resources for the benefit of all, including its complementors.

The MOS is designed as a two-sided structure both in terms of business model and technical architecture. Such platforms rely on externalities between developers and users. It is then rational for the platform owner to subsidize developers to reduce their technical and financial barriers to entry, and to encourage them to adopt the MOS. Each new developer contributes to the enhancement of the ecosystem as a whole, and benefits from it in return.

\subsubsection{The Provision of Boundary Resources}

According to Vezzoso, ${ }^{7}$ digital platforms are much more than mere demand aggregators, but have to be seen as catalysts for a system of complementary innovations. An Android-like platform is based on technical and institutional mechanisms that aim to promote and guarantee indirect network externalities between the different users of the platform. In a way, a third-party developer is also a customer of the platform: both access to the market and effective development of the product depend on the services provided by the platform owner. In other words, a platform is not reducible to a matching algorithm but is also a modular production network relying on complementary resources and investments as Moore (2006) has shown. ${ }^{8}$

As such, a platform's ability to attract key complementors is a key success factor. The MOS owner has to generate enough trust in the capacity to create collective value to encourage third-party investments in specific assets. In the

7 Simonetta Vezzoso, 'Open Digital Platforms and Antitrust: A More Technological Approach', in Oliver Budzinski and Julius Haucap (eds), Recht und Ökonomie (Nomos, 2020).

8 James F. Moore, 'Business ecosystems and the view of the firm', (2006) The Antitrust Bulletin, 51(1), pp. 31-75. 
case of Android, which came on the market later than Apple's iOS, it was positively a sine qua non condition for catch-up. Such modularity obviously generates efficiency gains. It reduces barriers to entry and ensures devices and services interoperability. Meanwhile, it limits costs and interface problems. As noted by Wen and Zhu:' 'By providing efficient matching or development kits, such platforms have also significantly lowered the barriers for many small firms or individuals to innovate and to market their products and services.'

The openness of the platform has to be analyzed both in terms of resources availability (IP, data, open source licenses, etc.) and of access policy. ${ }^{10}$ Start-ups entering the ecosystem obtain resources to interact with all other actors (Application Programming Interfaces - APIs and software development kits - SDKs). This allows the platform owner to attract innovative companies and ensure interoperability, while preserving its control over the ecosystem. The platform therefore provides its ecosystem members with resources to ensure interoperability of services, compatibility of developments and economies of scale and scope. ${ }^{11}$ This provision is essential to make possible the construction of a complex ecosystem involving heterogeneous and uncoordinated actors. According to von Hippel and Katz, ${ }^{12}$ these boundary resources transfer design capabilities to users.

These resources include every contractual or technical asset likely to interface third-parties' products and services with those of the platform. ${ }^{13}$ When available free of charge to new entrants, such assets drastically reduce barriers to entry, coordination and transaction costs: '[Their] use ... is aimed at lowering the often-large development and commercialization costs to new operations, therefore helping to create wider network effects ... ${ }^{14}$ (in other words, they secure and facilitate third-party investments, which generate

9 Wen Wen and Zhu Feng, 'Threat of Platform-Owner Entry and Complementor Responses: Evidence from the Mobile App Mark', (2019) Strategic Management Journal, 40(9), pp. 1336-1367.

10 Simonetta Vezzoso, n. 7.

11 Ben Eaton, Silvia Elauf-Calderwood, Carsten Sørensen and Youngjin Yoo, 'Distributed Tuning of Boundary Resources: The Case of Apple's iOS Service System', (2015) MIS Quarterly, 39(1), pp. 217-243.

12 Eric von Hippel and Ralph Katz, 'Shifting Innovation to Users via Toolkits', (2002) Management Science, 48, pp. 821-834, 824.

13 Ahmad Ghazawneh and Ola Henfridsson, 'Balancing Platform Control and External Contribution in Third-Party Development: The Boundary Resources Model', (2013) Information System Journal, 23, pp. 173-192.

14 Kristian Lauslahti, Juri Mattila and Timo Seppälä, 'Smart Contracts - How will Blockchain Technology Affect Contractual Practices?', (2017) ETLA Reports, 68, January, p. 7. 
complementary assets in return). ${ }^{15}$ It allows each app to adjust automatically to changes resulting from decentralized and uncoordinated decisions by all ecosystem members. ${ }^{16}$

However, this model of complementary investments involves heterogeneous firms with distinct bargaining power. The integrating firm, which acts as a gatekeeper and coordinator for third-party investments, is in a pivotal position. ${ }^{17}$ It is both a business provider and an orchestrator of technical developments. ${ }^{18}$

\subsubsection{An Attractive Business Model for All Its Stakeholders}

Beyond the abovementioned technical dimensions, integration into an ecosystem can also be financially attractive for complementors. The keystone player also has incentives to subsidize its complementors.

For instance, in Android, the Commission fined Google for having 'made payments to certain large manufacturers and mobile network operators on condition that they exclusively pre-installed the Google Search app on their devices' ${ }^{19}$ In this logic, the MOS owner redistributes to third-parties some of the network externalities generated jointly. As mentioned above, incentives can also be provided by making boundary resources available free of charge. This profit-sharing is mutually beneficial since it strengthens network effects. According to Lauslahti et al.:20 'Digital platform owners mostly benefit from sharing boundary resources with third-parties by capitalising on split revenue business models.'

Surplus redistribution among the ecosystem members can also give rise to price protection mechanisms. The US Supreme Court ruling in Apple v Pepper

15 David J. Teece, 'Profiting from Technological Innovation: Implications for Integration, Collaboration, Licensing and Public Policy', (1986) Research Policy, 15, pp. 285-305.

16 Ahmad Ghazawneh and Ola Henfridsson, 'Balancing Platform Control and External Contribution in Third-Party Development: The Boundary Resources Model', (2013) Information System Journal, 23, pp. 173-192.

17 Robin Mansell, 'Platforms of Power', (2015) Intermedia, 43(1), pp. 20-24.

18 Orla Lynskey, 'Regulating "Platform Power", (2017) LSE Law, Society and Economy Working Papers, 1/2017.

19 Google Android (case AT.40099) European Commission Decision, C(2018) 4761 final, 18 July 2018.

20 Kristian Lauslahti, Juri Mattila and Timo Seppälä, 'Smart Contracts - How will Blockchain Technology Affect Contractual Practices?', (2017) ETLA Reports No. 68, January, p. 7. 
illustrates this point. ${ }^{21}$ The question was whether transactions between app developers and end users are carried out under Apple's effective control. ${ }^{22}$ This case sheds light on the nature of the links between developers and ecosystem managers. ${ }^{23}$ An amicus curiae submitted to the Supreme Court shows the ambiguity of the relationship between the different stakeholders, which covers both an economic dependency relationship and a mechanism for redistributing the rent within the ecosystem. If an app developer is likely to accept unbalanced competition practices, is it because it fears some retaliation measures from the integrated firm, or because it also benefits from redistribution mechanisms?

In this case, app developers are not likely to seek damages for potential antitrust injuries from the exercise of Apple's monopsony power. Developers who bring suit against Apple risk jeopardizing their access to the App Store, as Apple can seek retribution against them in any of a myriad of different ways. In addition, many app developers may be unwilling to sue Apple for its monopolization of the app distribution market due to a perception that Apple may manipulate the pricing and sale of the apps in ways that ultimately benefit the developers. ${ }^{24}$

Indeed, as Vaheesan ${ }^{25}$ highlights, the rule imposed by Apple on the App Store, to impose prices ending in 99 cents has the effect of increasing developers' revenues by limiting price competition. For the monopsonic firm (Apple's App Store de facto is), it is also a way to redistribute part of its income to developers. The same intuition is highlighted by Posner ${ }^{26}$ who draws a parallel with the Microsoft case: 'in exchange for agreeing to exclusionary provisions in their contracts with Microsoft, the manufacturers received various benefits, including discounts, cooperation in development, and greatly enhanced computer sales via the continuous upgrading'.

21 US Supreme Court, Apple Inc v Pepper et al., Certiorari to the US Court of Appeal for the Ninth Circuit, 17-204, 13 May 2019.

22 Walid Chaiehloudj, 'Abuse of Dominant Position and Big-Tech: An Apple Store Case After the Android Affair?', (2018) Concurrences, 4-2018.

${ }_{23}$ The Supreme Court held that app users (e.g. indirect purchasers) could directly sue Apple for an allegedly anticompetitive commission overturning its Illinois Brick case law (Illinois Brick Co. v Illinois, 431 U.S. 720 (1977)).

24 Sandeep Vaheesan, Brief of Amicus Curiae Open Markets Institute in Support of Respondents, (2018) US Supreme Court, case 17-2004, Apple Inc v Robert Pepper et al., October, p. 3.

25 Sandeep Vaheesan, n. 24.

26 Eric Posner, Brief of Amicus Curiae Open Markets Institute in Support of Respondents, (2018) US Supreme Court, case 17-2004, Apple Inc v Robert Pepper et al., October, p. 18. 


\subsection{A SYMBIOSIS COVERING A SITUATION OF ECONOMIC DEPENDENCE?}

However, to access the ecosystem, complementors must accept the risk of swimming between sharks. ${ }^{27}$ Complementors' dependence comes from both the lack of interoperability between competing ecosystems, and the strong market concentration since platforms are naturally winner takes all markets. ${ }^{28}$ Briefly, platforms are coopetition markets in which firms share their resources to create value but compete to maximize their profits. ${ }^{29} \mathrm{With}$ respect to the incomplete contract theory, complementors - who make specific investments - are particularly exposed to a risk of contractual hold-up. ${ }^{30}$

The MOS is then a contracting nexus involving heterogeneous stakeholders in a value creation process. However, even if the coopetition model prevails, the bargain power is asymmetrically distributed among actors since only the integrator benefits from the regulatory power. ${ }^{31}$ Complementors rely on the pivotal firm both to develop their services and to access the market. The risks complementors have to assume are all the more important as the pivotal firm can collect data on their activity to compete with them ultimately. For instance, in September 2018, the EU Commission has announced the opening of a proceeding to investigate the way Amazon uses data related to the activity of independent merchants on its marketplace to adjust its own offers. ${ }^{32}$ Indeed, the pivotal firm owns a gatekeeper position it could take advantage of to reduce the visibility of the complementary offers through, for example, the manipula-

27 Luis Diestre and Nandini Rajagopalan, 'Are All Sharks Dangerous? New Biotechnology Venture and Partner Selection in R\&D Alliances', (2012) Strategic Management Journal, 33(10), pp. 1115-1134.

28 Feng Zhu and Marco Iansiti, 'Entry into Platform-based Markets', (2012) Strategic Management Journal, 33(1), pp. 88-106.

29 Adam Brandenburger and Barry J. Nalebuff, Co-opetition (Currency Doubleday, 1997).

30 Oliver E. Williamson, Market and Hierarchies: Analysis and Antitrust Implications (Free Press, 1975).

31 Kevin J. Boudreau and Andrei Hagiu, 'Platform Rules: Multi-Sided Platforms as Regulators', in Annabel Gawer (ed.), Platforms, Markets, and Innovation (Edward Elgar, 2009), pp. 163-191.

32 Dirck Auer, 'The Amazon Investigation and Europe's "Big Tech" Crusade', Truth on the Market, October, available at https://truthonthemarket.com/2018/10/21/ the-amazon-investigation-and-europes-big-tech-crusade/, accessed 16 December 2020. 
tion of its ranking. ${ }^{33}$ The pivotal firm can also buy promising start-ups before it becomes a potential threat, like Facebook's takeover of Instagram. ${ }^{34}$

Then, such platforms place complementors in a double situation of technical and economic dependence vis-à-vis the integrator. ${ }^{35}$ Technically, the platform owner can exclude third-party offers from the application store. Economically, exclusion strategies can be achieved through less favorable access conditions or, even more sharply, by bundling a substitute offer at no additional cost as a standard feature of the platform.

In platform-to-business cases, the Commission has concerns about unfair contractual clauses or practices, the opacity of trading conditions and the lack of clear criteria for resolving disputes involving third-parties and the platform owner. The Commission therefore aims to define 'principles of preventing abuse of market power and ensuring that platforms that serve as a gateway to downstream market do not become gatekeepers'. ${ }^{36}$ Platform owners have the unilateral power to deny (or to significantly impede) access to the market to third-party developers. This can be achieved, for instance, through dereferencing, modification of contractual conditions, discriminating between offers, etc. Such unilateral power results in the ability to impose unbalanced contractual conditions. ${ }^{37}$

In this regard, Vaheesan ${ }^{38}$ shows that Apple benefits from regulatory capacities over its complementors. It 'includes being made subject to the particular, and arbitrary, political and moral rules that Apple uses to regulate the nature of the apps that are available for sale to iPhone customers. And it includes being made subject to arbitrary, discriminatory manipulation in the act of shopping for and buying apps.' If Apple imposes unbalanced contractual terms to

33 Such as Zynga's position after the reduction in the number of games appearing on Facebook's newsfeed.

34 Li Zhuoxin and Agarwal Ashish, 'Platform Integration and Demand Spillovers in Complementary Markets: Evidences from Facebook's Integration of Instagram', (2017) Management Science, 63(10), pp. 3438-3458.

35 The Commission notes that economic dependence mainly occurs when the 'asymmetry between the relative market strength of a small number of leading platforms - not necessarily dominant in the sense of competition law - is combined with a highly fragmented supply-side of many small business users'. European Commission, Final Report on the E-commerce Sector Inquiry, 2017, COM(2017) 229 final, 10 May, p. 25.

36 European Commission, Impact Assessment Accompanying the Proposal for a Regulation on Promoting Fairness and Transparency for Business Users of Online Intermediation Services, 2018, SWD(2018) 138 final, 26 April.

37 Patrice Bougette, Oliver Budzinski and Frédéric Marty, 'Exploitative Abuse and Abuse of Economic Dependence: What Can We Learn from an Industrial Organization Approach?', (2019) Revue d'Economie Politique, 129(2), pp. 261-286.

38 Sandeep Vaheesan, n. 24, p. 6. 
third-parties, its retaliation capacities could also prevent it from potential lawsuits: 'Developers who sue Apple for antitrust violations run the risk of being removed from the App Store and losing their access to end users - a threat that is not entirely theoretical.' ${ }^{39}$ The same argument can be found in the amicus curiae produced in the same case by Eric Posner, ${ }^{40}$ which takes up on this point a reasoning already held by Hovenkamp: ${ }^{41}$ 'Many direct purchasers are "highly unlikely to sue" because they think they would be better off permitting an antitrust violation to continue rather than risking their relationship with the alleged violator.'

In most traditional coopetition models, companies cooperate upstream to create value and then compete downstream. In platforms models, downstream competition is distorted as long as the platform owner also controls the market access conditions. The platform is by itself an access lock and almost the only link between the ecosystem members and end users.

\subsection{FROM SYMBIOSIS TO KILL ZONE: WHY PIVOTAL FIRMS CAN BE LED TO EXCLUDE THEIR COMPLEMENTORS?}

Pivotal firm and complementors are then engaged in a complex process of value co-creation, but the former benefits from a strategic position it may take advantage of. In this third section, we explore market conditions in which platform owners have some strong incentives to exclude their complementors.

\subsubsection{Dissymmetry in Data Control that Can Lead to Exclusionary Strategies}

The 'cooperative' resource pooling mechanisms described above enable pivotal firms to detect, at a very early stage, promising new products or services, as well as potential disruptive innovation that could ultimately undermine their dominant positions.

In this context, takeover bids are the first means to prevent competitive threats in the long term. ${ }^{42}$ Exclusionary strategies are the second. Microsoft, for example, is alleged to have excluded Netscape and Real Network respectively from the internet browser and music player markets through those

\footnotetext{
Sandeep Vaheesan, n. 24, p. 12.

Eric Posner, n. 26, p. 16.

41 Herbert Hovenkamp, 'The Rationalization of Antitrust', (2003) Harvard Law Review, 116(3), pp. 917-944.

42 Thibault Schrepel, 'Predatory Innovation: The Definite Need for Legal Recognition', (2018) SMU Science and Technology Law Review, 21, pp. 19-73, p. 49.
} 
kind of practices. ${ }^{43}$ Such exclusionary practices may be analyzed as leverage strategies, or platform envelopment strategies, as referred to in the management science literature. Shared resources and users' relationships allow the platform owner entry into the complementor's market. ${ }^{44}$ Most of the time, the complementor has no chance in remaining competitive when a substitute offer is directly provided by the platform..$^{45}$ Control over data - but also broader client and technology knowledge - gives the platform owner the ability to implement nowcasting strategies: ${ }^{46}$ 'Nowcasting also represents a potent data-based weapon, not previously available for monopolies, to monitor new business models in real time. The nowcasting radar can help some dominant firms identify nascent competitive threats.'

The gradual replacement of offers developed by third-parties by homemade services is an attempt by the platform owner to capture the existing or future value. ${ }^{47}$ As described above, Microsoft's bundling strategy gave it the opportunity to extend its dominant position from the tying market (Windows) to two tied markets (the ones of Netscape and Real Player). Predatory innovations pursue the same goal. ${ }^{48}$

Such strategies lie in 'the modification of a technological platform and the technical design of a product - which are aimed at removing the compatibility of third-party technologies with those of a dominant firm, or at impairing competing technologies operation' ${ }^{49}$ In one case, exclusion is achieved through the voluntary degradation of interoperability. In the other, it is through the launch of a homemade product. Such a move would impair the competitiveness of existing complementary goods, and deter potential rivals to enter the market.

The platform owner can also exclude a complementor by degrading the performance of its offer, for instance in delaying the transmission of information needed for updates ${ }^{50}$ or via demoting strategy (as reproached to Google in the Google Shopping case). The EU Commission suspects Amazon to engage in such practices towards the independent resellers of its marketplace. Amazon could exploit aggregated commercial data, as well as unique sourcing capabilities, to detect and then self-distribute the bestsellers. Such an information

43 Simonetta Vezzoso, n. 7.

44 Thomas R. Eisenmann, Geoffrey Parker and Marshall W. Van Alstyne, 'Platforms Envelopment', (2011) Strategic Management Journal, 32(12), pp. 1270-1285.

$45 \quad$ Feng Zhu and Qihong Liu, n. 4.

46 Maurice E. Stucke and Allen P. Grunes, 'Data-Opolies: The US Point of View', (2017) Concurrences, 2-2017.

47 Joseph Farrel and Michael L. Katz, 'Innovation, Rent Extraction, and Integration in System Markets', (2000) Journal of Industrial Economics, 48(4), pp. 413-432.

48 Thibault Schrepel, n. 42, p. 45.

49 Thibault Schrepel, n. 42, p. 22.

50 Thibault Schrepel, n. 42, p. 28. 
asymmetry is incompatible with the principle of fair competition. ${ }^{51}$ As stated by the Commissioner:

The question here is about the data, because if you as Amazon get the data from the smaller merchants that you host ... do you then also use this data to do your own calculations? What is the new big thing, what is it that people want, what kind of offers do they like to receive, what makes them buy products? These concerns relate to the fact that Amazon acts as both a retailer in its own right and a platform for other retailers, which allegedly constitutes a 'conflict of interest'. ${ }^{52}$

This risk is also highlighted by Zhu and Liu. ${ }^{53}$ The latter, based on an empirical study on Amazon's marketplace, shows that 'Amazon's entry strategy is likely premised on acquiring new information after forming partnerships with third-party sellers.'

\subsubsection{Exclusion through Anti-fragmentation Agreements}

Exclusionary practices can also rely on anti-fragmentation agreements, as described above. ${ }^{54}$ Admittedly, such agreements can be defended on the basis of interoperability and security. But, as counterparts for the access to boundaries resources shared by the platform owner with no additional costs, these agreements $^{55}$ are also a powerful tool to prevent any disruption risk.

For example, within the Android ecosystem, terminal manufacturers had to accept the Mobile Applications Distribution Agreement (MADA) to get an Android license. Basically, MADA does not allow manufacturers to select apps on a discretionary basis, and even forces the pre-installation of several Google apps such as Search or Maps ${ }^{56}$ From an economic perspective, such a requirement makes sense as the platform is a two-sided one and the end users operate Google's services for free. Then, Google needs a critical mass of users to get a return on investment.

With MADA comes AFA, for anti-fragmentation agreements, which aim at impeding development of alternative versions of the MOS, called Android

\footnotetext{
51 Dirck Auer, n. 32.

52 M. Verstager, press conference of 18 September 2018. For a perspective and discussion of this case see Auer n. 32.

53 Feng Zhu and Qihong Liu, n. 4, p. 2620.

54 Frédéric Marty and Julien Pillot, 'With Uncertain Damage Theory Come Unpredictable Effects of Remedies: Libres Propos on the Android Case', (2018) Competition Policy International Antitrust Chronicle, December.

${ }_{55}$ Such as CDD (Compatibility Definition Document) and CTS (Compliance Test Suite).

56 Frédéric Marty and Julien Pillot, n. 54.
} 
forks. While third-parties in principle allowed modifying Android's source code (openly accessible) to create forks, in practice devices manufacturers had to commit not to sell even a single smartphone running on an Android fork if they want to pre-install Google's proprietary apps on their devices. When MADA can be justified by the economics of two-sided models, the rationale of AFA lies in the prevention of incompatibility issues. However, such a practice also reduces incentives to develop potential competitive offers to Android. Thus, the control over boundary resources gives the platform owner a strong (and defendable) competitive advantage. ${ }^{57}$

\subsubsection{Buyouts Strategies to Exclude Potential Competitors}

Not only are the major players in the digital economy continually fueling their growth through the acquisition of promising start-ups at a frenetic pace, ${ }^{58}$ but also these buyouts often involve companies that are part of their ecosystem. This is a usual practice in the biotechnology industry where innovation is mainly pushed by small and medium-sized firms. Indeed, in that industry, major companies - that are reluctant to assume the R\&D costs and uncertainties - prefer to buy companies (and patents) once these risks have been removed. However, things are different in the digital world where such acquisitions seem much more motivated by the need to prevent a potential competitive threat, rather than the necessity to support and fund the growth of promising start-ups..$^{59}$

Indeed, in digital markets, even the GAFA's (Google, Amazon, Facebook and Apple) dominance can be disputed by a challenger offering a disruptive product or service, ${ }^{60}$ such as Nokia in the telephony market. ${ }^{61}$ Some buyouts can then be seen as a weapon to prevent any disruption risks. Facebook's takeover of Instagram and the acquisition of Picasa by Google, as an attempt to respectively remain dominant in the social network market and to promote Google Photos, are two perfect examples. In a way, once a promising start-up has reached a certain stage of development, it would enter a kill zone. The

57 Simonetta Vezzoso, n. 7.

58 Kevin A. Bryan and Erik Hovenkamp, 'Start-up Acquisitions, Error Costs, and Antitrust Policy', (2020) University of Chicago Law Review, 87, pp. 331-356.

59 Eric Posner and Glen Weyl, Radical Markets - Uprooting Capitalism and Democracy for a Just Society (Princeton University Press, 2018).

60 Clayton M. Christensen, Michael E. Raynor and Rory McDonald, 'What Is Disruptive Innovation?', (2015) Harvard Business Review, December, p. 5.

${ }_{61}$ Timo O. Vuori and Quy N. Huy, 'Distributed Attention and Shared Emotions in the Innovation Process: How Nokia Lost the Smartphone Battle', (2016) Administrative Science Quarterly, 61, pp. 9-51. 
concept comes from Microsoft's practices towards its complementors in the 1990s, which, to some extent, could lead to an 'embrace, extend and extinguish' strategy. ${ }^{62}$ Every promising complementor is particularly exposed to a buy-out risk: 'they will eat their own children to live another day'. ${ }^{63}$

Third-parties can barely deal with such buy-out attempts, particularly because traditional response strategies, such as price competition, low-cost approaches or better user experience, are almost inefficient in the present case, ${ }^{64}$ if not impossible.$^{65}$ Indeed, two-sided platforms have a zero price business model and competition on the tied markets is based on quality. As the platform owner is vertically integrated and benefits from the gatekeeper advantage, it represents a very credible threat of market exclusion for complementors. ${ }^{66}$ With that in mind, the latter are all the more likely to accept a friendly takeover approach.

Besides, several structural factors increase the likelihood of kill zones as compared with the 1990s. First, numerous start-ups have the overall objective of being taken over by a leading company. Second, Tech Giants benefit from huge capacities in data capture and exploitation that give them the ability to detect potential competitive threats much earlier than in the past. Third, dominant firms own an unprecedented stock of scarce resources, including engineers. As most of the start-ups just cannot offer comparable salary conditions, they often appear less attractive than Tech Giants.

Finally, takeovers of complementors are also the result of competition among platforms. In the Apple-Shazam M\&A case, ${ }^{67}$ the Commission questioned how access to Shazam's data could distort competition both on the music streaming market and the one for devices. As a vertically integrated group, Apple could be encouraged to downgrade Shazam's music recognition algorithm for competitors' customers ${ }^{68}$ The Apple-Shazam case shows how

${ }^{62}$ Noah Smith, 'Big Tech Sets up a “Kill Zone” for Industry Upstarts' (Bloomberg Opinion, 7 November 2018).

63 'American Tech Giants Are Making Life Tough for Start-Ups', The Economist, 2 June 2018.

64 Benjamin Edelman and Damien Geradin, 'An Introduction to the Competition Law and Economics of Free', (2018) Competition Policy International Antitrust Chronicle, September.

${ }_{65}$ Damien Geradin, 'What Should EU competition Policy Do to Address the Concerns Raised by Digital Platforms' Market Power', (2018) working paper, available at https://ssrn.com/abstract=3257967, accessed 16 December 2020.

${ }^{66}$ Friso Bostoen, 'Online Platforms and Vertical Integration: The Return of Margin Squeeze?', (2018) Journal of Antitrust Enforcement, 6(3), pp. 355-381.

67 Case M.8788 Apple-Shazam, European Commission, 6 September 2018.

68 Nicolo Zingales, 'Apple/ Shazam/ Data is Power, But Not a Problem Here', (2018) Competition Policy International, December. 
one takeover can hinder competition when it results in granting the dominant firm an essential asset or decisive informational advantage. One could wonder if requirements usually held in merger control procedures are well designed to assess how the concentration of massive (and initially fragmented) users' data is likely to distort competition in the long term.

\subsection{WHAT ROLE FOR COMPETITION RULES ENFORCEMENT?}

Strategic relationships between platform owners and complementors are complex. As coopetition can meanwhile generate procompetitive and anticompetitive effects, such cases have to be undertaken with the greatest care by competition agencies, whether it be for assessing the damage to innovation and competition or for designing efficient remedies.

\subsubsection{How to Assess the Potential Damage to Innovation and Competition?}

\subsubsection{Fair expansion strategies or exclusionary abuses?}

Most complementors are fully aware about the risks associated with two-sided models when the platform owner is (or could be) integrated both vertically and horizontally. They could then adjust their ex ante behavior and strategy in order to avoid the kill zone, e.g. deter the platform owner from extending its market. ${ }^{69}$ If the threat of integration is high, R\&D investments shift to other markets and functionalities as the risk of contractual hold-up increases. Moreover, the effective entry of the platform owner is often beneficial to consumers in the short term as it reduces transaction costs and underinvestment bias. ${ }^{70}$

However, uncertainties about the future conduct of the platform owner are likely to dissuade third-parties from entering into long-term relationships and making specific investments. Such a situation may reduce further incentives to innovate. ${ }^{71}$ As two-sided platforms are mostly operated at no cost on the end user side, exclusion of complementors through vertical integration may not reduce the consumer welfare if the platform owner provides more efficient or less expensive substitutes. However, such a practice harms innovation as it

${ }^{69}$ Such a result has been established for independent vendors on the Amazon platform. Feng Zhu and Qihong Liu, n. 4.

70 Wen Wen and Zhu Feng, n. 9.

71 Such as in Microsoft (2004), in which the Commission stated that 'restrictions should not create disincentives to compete with Microsoft, or unnecessarily restrain the ability of the beneficiaries to innovate'. 
restricts freedom of choice as well as preventing the emergence of alternative technological trajectories.

With such unbalanced relationships, what are the options open to complementors? Niche strategies are a first option. Non-cooperative strategies that consist in restricting data sharing with the platform owner are a second one. ${ }^{72}$ However, the sustainability of the latter option is somewhat hard to believe since the platform owner often has control over end users data. In any case, the platform owner is able to exclude from the market a complementor that could eventually prove to be a potential competitor. Such a practice could challenge the contestability of the market and give rise to irreversible dominant positions. Then, despite obvious information asymmetries, competition agencies have to balance pro and anticompetitive effects and determine how exclusionary practices could harm competition, innovation and consumers in the long term.

\subsubsection{In M\&A cases}

In M\&A cases, several questions may be asked. First, what are the revenue and the market share of the target? Most of the targeted start-ups are not desirable because of their performance indicators, but for their technologies, their patents and sometimes their brands and services by themselves. In that respect, usual structural indicators (such as HHI) say little about potential competitive risks. ${ }^{73}$ Those are all the higher as platform owners are structurally focused on the future markets and compete in the search for new and low end market footholds. They engage corporate ventures in frontier technological areas, and attack peripheral markets. ${ }^{74}$ As platform owners follow mimetic conglomerate

72 Feng Zhu and Qihong Liu, n. 4, p. 2637.

73 Traditional indicators should be completed by, for example, the stock market capitalization of the target (as proxy of the future consolidated cash flow) future or the mass and quality of data the consolidated group will control. The German reform on merger control that came into effect on 31 March 2017 was grounded on these principles. In addition to the traditional market share criteria, the value of the consideration paid in return for the transaction is now taken into account. If the amount exceeds $€ 400$ million, the deal is subject to preliminary checks, with no regards to the parties' revenue or market shares. Heike Schweitzer, Julius Haucap, Wolgang Kerber and Robert Welker, 'Modernization of Abuse Control for Companies with Market Power', (2018) DICE Consult, Düsseldorf. More generally, should we in the case of innovation markets consider that patents or R\&D expenditures can be adopted as indicators of the likelihood of the consolidated group to distort competition in the future? Richard J. Gilbert and Steven C. Sunshine, 'Incorporating Dynamic Efficiency Concerns in Merger Analysis: The Use of Innovation Markets', (1994) Antitrust Law Journal, 63, p. 569 et seq.

74 Nicolas Petit, Big Tech and the Digital Economy: The Moligopoly Scenario (Oxford University Press 2020). 
expansion schemes, customer lock-in into silos and market foreclosure are two serious risks in the long term that antitrust agencies have to take into account.

At this point, one may argue that a specific regime should be implemented for every M\&A project that involves a dominant firm and one complementor. But, vertical integration is not problematic in itself. As mentioned above, in the biotech industry, it is usual to let small and medium-sized firms endorse most of the R\&D expenditures, and to integrate the successful innovators afterwards. Thus, adopting a specific regime could distort established investment schemes in some industries. Similarly, in IT sectors where there are strong needs for service convergence and integration, reinforcing merger control proceedings may finally prove harmful to end users. However, as we have seen above, excessive market concentration can result in technological monopoly and huge switching costs for end users likely to foreclose markets in the short term, and restrict the development of alternative technological trajectories in the long term. How to balance pro and con effects in a context of still incomplete and asymmetric information?

To that extent, the French competition agency proposes to implement an ex post control procedure for mergers. ${ }^{75}$ Such control already exists in some EU Member States, including the UK and Sweden, 'where particular grounds exist', e.g. when the competition agency considers that the nature of merger calls for an observation period to scrutinize its impact on the economy. Two questions can then be asked. First, how long should this observation period be? Second, how to deal with the legal uncertainty that such observation period introduces? On that particular point, the French competition agency proposes to publish clear guidelines and to limit the period in which such an ex post control could be implemented from six months to two years. Even a shortened period may seem very long in digital industries.

\subsubsection{What are the Effects of Competitive Remedies?}

In short, ecosystems are mainly coopetitive, and involve heterogeneous actors in a process of collective (and shared) value creation. Such a context makes it very difficult to assess the economic pros and cons of M\&A or unilateral expansion strategies when a platform owner is involved. The same goes for designing efficient remedies, e.g. remedies likely to preserve the contestability of the markets without harming end users.

75 On 20 October 2017, the French Competition Authority launched a public consultation to modernize and simplify French merger control regime. See the public document at: https://www.autoritedelaconcurrence.fr/sites/default/files/consultation_c oncentrations20oct17.pdf, accessed 13 January 2021. 
For example, in Android, the EU Commission required Google to bring some anticompetitive practices to an end (pre-installation of Google's home services, including Search, Chrome and Play Store; financial incentives conditioned to exclusive installation of Google Search, and anti-fragmentation agreements). However, the EU Commission did not ignore the two-sided nature of the market, as it states: 'the decision does not prevent Google from putting in place a reasonable, fair and objective system to ensure the correct functioning of Android devices using Google proprietary apps and services, without however affecting device manufacturers' freedom to produce devices based on Android forks'.

To comply with the Commission's injunctions, Google proposed a set of remedies, including:

- Disjoint distribution of Google Play's Search and Chrome applications;

- Disjoint and non-exclusive distribution of free licenses for Search and Chrome;

- Full licensing for Google Play and eight other services (including Gmail, Google Maps ...), with price discrimination regarding the range of the device. The end of free access is intended to compensate the loss of the two-sided effect described above;

- Removal of anti-fragmentation clauses. Then, manufacturers will be able to develop devices running on Android fork, as long as they inform consumers about the potential lack of compatibility with apps developed for the official MOS.

Although these remedies do not challenge the MOS model per se, they still partially undermine it. For example, financial incentives towards manufacturers and phone operators could be seen as a way to redistribute part of the co-created value. Forcing Google to put an end to that practice may then have undesirable effects, such as increase in price in the device market, especially for entry-level products. Similarly, putting an end to anti-fragmentation clauses may incite Google to replace Android by a new MOS. Such a move would impose huge switching costs both for undertakings and end users. It is no accident if Google is already working on a next generation MOS, expressly confirmed under the codename 'Fushia'. But with no need to catch-up a leading edge technology this time, as it was in 2007 when Apple disrupted the smartphone market, would Google maintain an open architecture for Fushia?

Consequently, not only may such remedies not prove efficient, but they also may arrive too late while several Asian original equipment managers (OEMs) (such as ZTE and Huawei) presently work on their proprietary MOS. Interestingly, it is not antitrust proceedings but international trade policy considerations (especially tensions between the United States and China) that 
encourage OEMs to enter the MOS market. Nevertheless, from the economic perspective, the more OEMs, the more fragmented are investments, the more important are development costs to avoid interoperability issues.

Moreover, regardless of the EU Commission decision in Android and how US jurisdictions will settle in Apple v Pepper, it is almost fuzzy to forecast how relationships between MOS owners and complementors - especially native app developers ${ }^{76}$ - will evolve in the near future. With the progressive emergence of Progressive Web Apps (PWAs), interdependence between platform owners and complementors could no longer be taken for granted. PWAs are less costly, as these are not specific to one given ecosystem, and entail less update costs than native apps. PWAs are also somewhat user friendly since they save storage space and offer offline functionalities. The more PWAs will be widespread, the less the symbiosis model will be relevant.

For all these reasons, the efficiency of remedies is nearly impossible to attest from an ex ante basis. The nature of the tradeoff will almost exclusively depend on how firms will adjust their business and technology strategies following the proclamation of remedies, and how they would have behaved in their absence in the long run. As competition agencies have few - if any control on these issues, the risk of moral hazard looks extremely - and perhaps unwisely - important.

\section{CONCLUSION}

MOS are the keystones of very complex B2B relationships between the platform owner and complementors. Such coopetition relationships in two-sided markets have both technical and business justifications. P2B cooperation has the advantage to share innovation risks and investments among several firms, and to create shared value in return.

However, such a market organization confers a strong structural advantage on the platform owner as it benefits from a position of market gatekeeper, and controls most of the users' data. The platform owner could take advantage of its specific market position to engage in some exclusionary practices, such as unfair envelopment strategies, likely to hurt innovation. ${ }^{77}$ While such practices do not harm consumer welfare in the short term (as services are most likely to be proposed at no additional cost once integrated by the platform owner), they

76 At an early stage, the development of native apps required numerous third parties and entailed significant costs (particularly with regard to update constraints). Nevertheless, these native apps have not always met expectations, offering sometimes low user experience and value added compared to a website with responsive design capabilities.

77 Damien Geradin, n. 65. 
could restrict freedom of choice in the long term as they prevent the emergence of alternative technological trajectories.

There are ongoing discussions on the standard that competition agencies should apply to cases that involve two-sided markets. For example, the effective competition standard developed by Marshall Steinbaum and Maurice Stucke encompasses not only the consumer welfare dimension, but also seeks to protect/preserve competitive marketplaces, undertakings with no market power and more generally atomistic competition, free access to the market, and future opportunities for innovative firms. ${ }^{78}$

However, it is not clear whether such a standard could be efficient in two-sided digital markets. Indeed, two questions remain. First, how can we characterize any market power if the relevant market itself cannot be unambiguously defined? As Oliver Budzinski and Annika Stöhr note, market power is a distributed and relative phenomenon whose definition requires a case-by-case basis. Perhaps competition laws are less appropriate than contract laws to deal with that kind of case. ${ }^{79}$

Second, is it worth extending the special responsibilities incumbent on dominant firms to every complementor and, more largely, every member of its proprietary ecosystem? We have shown that a platform owner exercises quasi-regulatory power over its ecosystem as it can unilaterally determine and change the prices and market access conditions. It can also influence complementors' investment decisions. In a way, as long as rival ecosystems exist, most of the situation of economic dependence results from (more or less) efficient and objective strategic choices. However, when a single and natural standard emerges, complementors have no more exit options. At this point, competitive risks have unquestionably to be taken into consideration regardless of the complex nature of the market organization or the potential risks flowing from imperfect remedies.

78 Marshall Steinbaum and Maurice Stucke, 'The Effective Competition Standard - A New Standard for Antitrust', (2020) University of Chicago Law Review, 86, pp. 595-623.

79 Oliver Budzinski and Annika Stöhr, 'Competition Policy Reform in Europe and Germany - Institutional Change in the Light of Digitalization', (2019) European Competition Journal, 15(1), pp. 15-54. 